\title{
The Outline of the Strategy for Solving Knowledge Inconsistencies in a Process of Agents' Opinions Integration
}

\author{
Radoslaw Katarzyniak and Agnieszka Pieczyńska \\ Institute of Information Science and Engineering, Wroclaw University of Technology, \\ Wybrzeze Wyspianskiego 27, 50-370 Wroclaw, Poland \\ \{radoslaw.katarzyniak, agnieszka.pieczynska\}@pwr.wroc.pl
}

\begin{abstract}
In this paper a strategy for integration of agents' prepositional attitudes is proposed in order to solve the semantic inconsistency between opinions of members of agents' population. In proposed algorithm all the agents' answers are transformed into fuzzy set equivalents and then final formula representing the agreement of all opinions is obtained.
\end{abstract}

\section{Introduction}

Lack of central mechanisms of control in multiagent systems caused that the states of some objects from external world might be for some agents not known. In such cases the agents must be equipped with mechanisms that let them cope with incomplete knowledge. In our approach this mechanism is called the algorithm of messages generation [4],[5]. As an input of this algorithm the overall agent's knowledge base is given and as an output the prepositional attitudes (opinions) in which the content is related to the current states of objects. The agents' opinions are in the form of logic formulas [4],[9]. Each formula is consisted of the modal operator and two indices to the properties that are observed by the agent $a \in A$ in the object $o_{z} \in O$ at the time point $t_{n} \in T$ or are estimated on the basis of agent's previous experiences applying the algorithm for the messages generation. The co-existence of these properties in objects from the set $\mathrm{O}$ is reflected by logic connectives such as: conjunction, exclusive alternative or alternative. The language is given as: $\Omega=\left\{\mathrm{OP}^{\mathrm{a}}\left(\mathrm{P}_{\mathrm{i}}\left(\mathrm{o}_{\mathrm{z}}\right) \wedge \mathrm{P}_{\mathrm{j}}\left(\mathrm{o}_{\mathrm{z}}\right)\right)\right.$, $\mathrm{OP}^{\mathrm{a}}\left(\mathrm{P}_{\mathrm{i}}\left(\mathrm{o}_{\mathrm{z}}\right) \wedge \neg \mathrm{P}_{\mathrm{j}}\left(\mathrm{o}_{\mathrm{z}}\right)\right), \mathrm{OP}^{\mathrm{a}}\left(\neg \mathrm{P}_{\mathrm{i}}\left(\mathrm{o}_{\mathrm{z}}\right) \wedge \mathrm{P}_{\mathrm{j}}\left(\mathrm{o}_{\mathrm{z}}\right)\right), \mathrm{OP}^{\mathrm{a}}\left(\neg \mathrm{P}_{\mathrm{i}}\left(\mathrm{o}_{\mathrm{z}}\right) \wedge \neg \mathrm{P}_{\mathrm{j}}\left(\mathrm{o}_{\mathrm{z}}\right)\right), \operatorname{Bel}^{\mathrm{a}}\left(\mathrm{P}_{\mathrm{i}}\left(\mathrm{o}_{\mathrm{z}}\right) \vee \mathrm{P}_{\mathrm{j}}\left(\mathrm{o}_{\mathrm{z}}\right)\right)$, $\left.\operatorname{Bel}^{\mathrm{a}}\left(\mathrm{P}_{\mathrm{i}}\left(\mathrm{O}_{\mathrm{z}}\right) \vee \mathrm{P}_{\mathrm{j}}\left(\mathrm{O}_{\mathrm{z}}\right)\right)\right\}$, where $\mathrm{OP}=\{\mathrm{Bel}$, Pos, Know $\}$. If the states of the objects are estimated on the basis of stored experiences then the modal operator of belief (Bel) or possibility (Pos) is used otherwise - the modal operator of knowledge (Know). For example for the formula $\operatorname{Pos}^{\mathrm{a}}\left(\mathrm{P}_{\mathrm{i}}\left(\mathrm{O}_{\mathrm{z}}\right) \wedge \mathrm{P}_{\mathrm{j}}\left(\mathrm{O}_{\mathrm{z}}\right)\right)$ the spoken language interpretation is: In my (agent's a) opinion it is possible that the object $\mathrm{o}_{\mathrm{z}}$ has the property $\mathrm{P}_{\mathrm{i}}$ and the property $P_{j}$. Each modal operator has its numerical equivalent respectively: $\gamma_{\mathrm{Know}}, \gamma_{\mathrm{Bel}}$ and $\gamma_{\text {Pos }}$ that represents the level of agent's confidence. Additionally with each formula coefficient support $\alpha_{p}$ is correlated (see section 3). If an agent at the particular time point cannot perceive the current state of particular object from external world and the results of the algorithm for the message generation are 
unsatisfied it asks other agents about their opinions. The agents send the answers that are the results of direct observation or applying the algorithm for messages generation. Due to the natural inconsistencies between prepositional attitudes carried out by different members of agents' population the incoming language responses can be different as regards to the used logic connectives in formulas and modal operators. Therefore, the agent interested in integration all these opinions, needs to apply certain strategies for semantic conflict resolution [5]. Proposed strategy is based on the idea of language grounding that states that each language formula needs to be related to a certain meaning embodied in private empirical experiences [1],[2],[3],[7].

\section{A Strategy for the Integration of Conflicting Opinions}

\subsection{Basic Postulates}

\section{Postulates in relation to the states of objects:}

1. If at the time point $t_{k}$ the object $o_{z}$ possesses both the property $P_{i}$ and $P_{j}$ then it belongs to the class of objects $\mathrm{O}_{1}\left(\mathrm{t}_{\mathrm{k}}\right) \subseteq \mathrm{O}$.

2. If at the time point $t_{k}$ the object $o_{z}$ possesses the property $P_{i}$ and doesn't posses the property $\mathrm{P}_{\mathrm{j}}$ then it belongs to the class of objects $\mathrm{O}_{2}\left(\mathrm{t}_{\mathrm{k}}\right) \subseteq \mathrm{O}$.

3. If at the time point $t_{k}$ the object $o_{z}$ doesn't posses the property $P_{i}$ and possesses the property $\mathrm{P}_{\mathrm{j}}$ then it belongs to the class of objects $\mathrm{O}_{3}\left(\mathrm{t}_{\mathrm{k}}\right) \subseteq \mathrm{O}$.

4. If at the time point $t_{k}$ the object $o_{z}$ doesn't posses neither the property $P_{i}$ and $P_{j}$ then it belongs to the class of objects $\mathrm{O}_{4}\left(\mathrm{t}_{\mathrm{k}}\right) \subseteq \mathrm{O}$.

5. If at the time point $t_{k}$ the object $o_{z}$ possesses either the property $P_{i}$ or $P_{j}$ then it belongs to the class of objects $\mathrm{O}_{5}\left(\mathrm{t}_{\mathrm{k}}\right) \subseteq \mathrm{O}$.

6. If at the time point $t_{k}$ the object $\mathrm{o}_{\mathrm{z}}$ possesses the property $\mathrm{P}_{\mathrm{i}}$ or $\mathrm{P}_{\mathrm{j}}$ then it belongs to the class of objects $\mathrm{O}_{6}\left(\mathrm{t}_{\mathrm{k}}\right) \subseteq \mathrm{O}$.

\section{Postulates in relation to the messages:}

1. With each message a support coefficient $\alpha_{p}, p \in\{1,2, \ldots, 6\}$ is associated.

2. If an agent sends a message with conjunction as a logic connective then the support coefficient $\alpha_{1}, 1=1,2,3,4$ is equal 1 . The state of an object $o_{z}$ is unequivocally specified.

3. If an agent sends a message with exclusive alternative as a logic connective then the support coefficient $\alpha_{5}$ is equal 0.5 . The state of an object $\mathrm{o}_{\mathrm{z}}$ is not unequivocally specified. Two states of affairs are considered: 1) an object $\mathrm{o}_{z}$ possesses the property $P_{i}$ and doesn't posses the property $P_{j}$ either 2) object $o_{z}$ doesn't posses the property $\mathrm{P}_{\mathrm{i}}$ and possesses the property $\mathrm{P}_{\mathrm{j}}$.

4. If an agent sends a message with alternative as a logic connective then the support coefficient $\alpha_{6}$ is equal 0.3 . The state of an object $o_{z}$ is not unequivocally specified and three states of affairs are considered: 1) an object $\mathrm{o}_{z}$ possesses the property $\mathrm{P}_{\mathrm{i}}$ and possesses the property $\mathrm{P}_{\mathrm{j}}$ either 2 ) $\mathrm{o}_{\mathrm{z}}$ possesses the property $\mathrm{P}_{\mathrm{i}}$ and doesn't posses the property $\mathrm{P}_{\mathrm{j}}$ either 3 ) $\mathrm{o}_{\mathrm{z}}$ doesn't posses the property $\mathrm{P}_{\mathrm{i}}$ and possesses the property $\mathrm{P}_{\mathrm{j}}$. 
5. Each message $\varphi_{\mathrm{a}}$ about the state of an object $\mathrm{o}_{\mathrm{z}}$ can be transformed into its firstlevel $\mathrm{fs}^{1}{ }_{\mathrm{a}}\left(\mathrm{o}_{\mathrm{z}}\right)$ and second-level $\mathrm{fs}^{2}{ }_{\mathrm{a}}\left(\mathrm{o}_{\mathrm{z}}\right), \quad \mathrm{a}=\left\{1,2, \ldots\right.$, card( $\left.\left(\mathrm{A}^{\prime}\right)\right\}$ semantically equivalent fuzzy set representation. First-level fuzzy set representation $\mathrm{fs}_{\mathrm{a}}{ }_{\mathrm{a}}\left(\mathrm{o}_{\mathrm{z}}\right)$ represents only the state of an object in relation to the co-existence of the properties $P_{i}$ and $P_{j}$ in the object $o_{z}$, but in the second-level representation $\mathrm{fs}^{2}{ }_{\mathrm{a}}\left(\mathrm{o}_{\mathrm{z}}\right)$ also the power of agent's beliefs is taken into consideration.

6. If two first-level fuzzy set representations $\mathrm{fs}_{\mathrm{a}}{ }_{\mathrm{a}}\left(\mathrm{o}_{\mathrm{z}}\right)$ and $\mathrm{fs}^{1}{ }_{\mathrm{b}}\left(\mathrm{o}_{\mathrm{z}}\right)$ consist a support coefficient $\alpha_{1}, l \in\{1,2,3,4\}$ then the support levels for the correlated formulas $\varphi_{a}$ and $\varphi_{\mathrm{b}}$ as a consensus opinion about the state of an object $\mathrm{o}_{\mathrm{z}}$ are mutually equal.

7. If there is a support coefficient $\alpha_{1}, l \in\{1,2,3,4\}$ in the first-level fuzzy set representation $\mathrm{fs}^{1}{ }_{\mathrm{a}}\left(\mathrm{O}_{\mathrm{z}}\right)$ and $\alpha_{5}$ (or $\alpha_{6}$ ) in the first-level fuzzy set representation $\mathrm{fs}^{1}{ }_{\mathrm{b}}\left(\mathrm{O}_{\mathrm{z}}\right)$, then the support level for the formula $\varphi_{\mathrm{a}}$ as a consensus opinion about the state of an object $\mathrm{o}_{\mathrm{z}}$ is higher than the one for the formula $\varphi_{\mathrm{b}}$.

8. If there is a support coefficient $\alpha_{5}$ in the first-level fuzzy set representation $\mathrm{fs}_{\mathrm{a}}{ }_{\mathrm{a}}\left(\mathrm{o}_{\mathrm{z}}\right)$ and $\alpha_{6}$ in the first-level fuzzy set representation $\mathrm{fs}^{1}{ }_{\mathrm{b}}\left(\mathrm{o}_{\mathrm{z}}\right)$, then the support level for the formula $\varphi_{\mathrm{a}}$ as a consensus opinion about the state of an object $\mathrm{o}_{\mathrm{z}}$ is higher than the one for the formula $\varphi_{b}$.

\section{2 The Idea of the Algorithm for the Integration Prepositional Attitudes}

Input: The set of answers $\left.\Upsilon=\left\{\varphi_{1}, \varphi_{2}, \ldots, \varphi_{\text {card( }} \mathrm{A}^{\prime}\right)\right\}$ sent by the agents from $\mathrm{A}^{\prime} \subseteq \mathrm{A}$.

Output: The opinion $\varphi_{C}$ about the state of an object $o_{z}$ in relation to the properties $P_{i}$ and $\mathrm{P}_{\mathrm{j}}$ with the confidence coefficient $\gamma_{\mathrm{C}}$.

Parameters: $\quad \gamma_{\mathrm{Know}}=1, \gamma_{\mathrm{Bel}}=0.7, \gamma_{\mathrm{Pos}}=0.4, \delta$ - the accepted value of tolerance in relation to the support function's value.

Step 1. Transform each formula $\varphi_{\mathrm{a}}$ into its first-level fuzzy set equivalent $\mathrm{fs}_{\mathrm{a}}{ }_{\mathrm{a}}$ as follows:

$$
\begin{aligned}
& \text { if } \varphi_{\mathrm{a}}=\mathrm{OP}^{\mathrm{a}}\left(\mathrm{P}_{\mathrm{i}}\left(\mathrm{o}_{\mathrm{z}}\right) \wedge \mathrm{P}_{\mathrm{j}}\left(\mathrm{o}_{\mathrm{z}}\right)\right) \text { then fs }{ }_{\mathrm{a}}{ }_{\mathrm{a}}\left(\mathrm{o}_{\mathrm{z}}\right)=\left\{\left(\mathrm{k}_{1}, 1\right),\left(\mathrm{k}_{2}, 0\right),\left(\mathrm{k}_{3}, 0\right),\left(\mathrm{k}_{4}, 0\right)\right\}^{\gamma} \\
& \text { if } \varphi_{\mathrm{a}}=\mathrm{OP}^{\mathrm{a}}\left(\mathrm{P}_{\mathrm{i}}\left(\mathrm{o}_{\mathrm{z}}\right) \wedge \neg \mathrm{P}_{\mathrm{j}}\left(\mathrm{o}_{\mathrm{z}}\right)\right) \text { then } \mathrm{fs}^{1}{ }_{\mathrm{a}}\left(\mathrm{o}_{\mathrm{z}}\right)=\left\{\left(\mathrm{k}_{1}, 0\right),\left(\mathrm{k}_{2}, 1\right),\left(\mathrm{k}_{3}, 0\right),\left(\mathrm{k}_{4}, 0\right)\right\}^{\gamma} \\
& \text { if } \varphi_{\mathrm{a}}=\mathrm{OP}^{\mathrm{a}}\left(\neg \mathrm{P}_{\mathrm{i}}\left(\mathrm{o}_{\mathrm{z}}\right) \wedge \mathrm{P}_{\mathrm{j}}\left(\mathrm{o}_{\mathrm{z}}\right)\right) \text { then } \mathrm{fs}^{1}{ }_{\mathrm{a}}\left(\mathrm{o}_{\mathrm{z}}\right)=\left\{\left(\mathrm{k}_{1}, 0\right),\left(\mathrm{k}_{2}, 0\right),\left(\mathrm{k}_{3}, 1\right),\left(\mathrm{k}_{4}, 0\right)\right\}^{\gamma} \\
& \text { if } \varphi_{\mathrm{a}}=\mathrm{OP}^{\mathrm{a}}\left(\neg \mathrm{P}_{\mathrm{i}}\left(\mathrm{o}_{\mathrm{z}}\right) \wedge \neg \mathrm{P}_{\mathrm{j}}\left(\mathrm{o}_{\mathrm{z}}\right)\right) \text { then } \mathrm{fs}^{1}{ }_{\mathrm{a}}\left(\mathrm{o}_{\mathrm{z}}\right)=\left\{\left(\mathrm{k}_{1}, 0\right),\left(\mathrm{k}_{2}, 0\right),\left(\mathrm{k}_{3}, 0\right),\left(\mathrm{k}_{4}, 1\right)\right\}^{\gamma} \\
& \text { if } \varphi_{\mathrm{a}}=\mathrm{OP}^{\mathrm{a}}\left(\mathrm{P}_{\mathrm{i}}\left(\mathrm{o}_{\mathrm{z}}\right) \underline{\vee} \mathrm{P}_{\mathrm{j}}\left(\mathrm{o}_{\mathrm{z}}\right)\right) \text { then } \mathrm{fs}^{1}{ }_{\mathrm{a}}\left(\mathrm{o}_{\mathrm{z}}\right)=\left\{\left(\mathrm{k}_{1}, 0\right),\left(\mathrm{k}_{2}, 0.5\right),\left(\mathrm{k}_{3}, 0.5\right),\left(\mathrm{k}_{4}, 0\right)\right\}^{\gamma} \\
& \text { if } \varphi_{\mathrm{a}}=\mathrm{OP}^{\mathrm{a}}\left(\mathrm{P}_{\mathrm{i}}\left(\mathrm{o}_{\mathrm{z}}\right) \vee \mathrm{P}_{\mathrm{j}}\left(\mathrm{o}_{\mathrm{z}}\right)\right) \text { then fs }{ }^{1}{ }_{\mathrm{a}}\left(\mathrm{o}_{\mathrm{z}}\right)=\left\{\left(\mathrm{k}_{1}, 0.3\right),\left(\mathrm{k}_{2}, 0.3\right),\left(\mathrm{k}_{3}, 0.3\right),\left(\mathrm{k}_{4}, 0\right)\right\}^{\gamma}
\end{aligned}
$$

where $\mathrm{OP} \in\{$ Know, Bel, Pos $), \gamma$ represents the level of agent's confidence and is correlated with modal operators as follows: if $\mathrm{OP}=\mathrm{Know}$ then $\gamma=\gamma_{\mathrm{Know}}=1$, if $\mathrm{OP}=\mathrm{Bel}$ then $\gamma=\gamma_{\mathrm{Bel}}=0.7$, if $\mathrm{OP}=$ Know then $\gamma=\gamma_{\text {Pos }}=0.4$

Step 2. Transform each first-level fuzzy set representation $\mathrm{fs}^{1}{ }_{\mathrm{a}}\left(\mathrm{o}_{\mathrm{z}}\right)$ into second-level fuzzy set representation $\mathrm{fs}^{2}{ }_{\mathrm{a}}\left(\mathrm{o}_{\mathrm{z}}\right)$ as follows:

$$
\begin{aligned}
& \text { if fs }{ }_{\mathrm{a}}\left(\mathrm{o}_{\mathrm{z}}\right)=\left\{\left(\mathrm{k}_{1}, 1\right),\left(\mathrm{k}_{2}, 0\right),\left(\mathrm{k}_{3}, 0\right),\left(\mathrm{k}_{4}, 0\right)\right\}^{\gamma} \text { then fs }{ }^{2}{ }_{\mathrm{a}}\left(\mathrm{o}_{\mathrm{z}}\right)=\left\{\left(\mathrm{k}_{1}, \mathrm{f}_{1}(1, \gamma)\right),\left(\mathrm{k}_{2}, 0\right),\left(\mathrm{k}_{3}, 0\right),\left(\mathrm{k}_{4}, 0\right)\right\} \\
& \text { if fs }{ }_{\mathrm{a}}{ }_{\mathrm{a}}\left(\mathrm{o}_{\mathrm{z}}\right)=\left\{\left(\mathrm{k}_{1}, 0\right),\left(\mathrm{k}_{2}, 1\right),\left(\mathrm{k}_{3}, 0\right),\left(\mathrm{k}_{4}, 0\right)\right\}^{\gamma} \text { then fs }{ }_{\mathrm{a}}{ }_{\mathrm{a}}\left(\mathrm{o}_{\mathrm{z}}\right)=\left\{\left(\mathrm{k}_{1}, 0\right),\left(\mathrm{k}_{2}, \mathrm{f}_{2}(1, \gamma)\right),\left(\mathrm{k}_{3}, 0\right),\left(\mathrm{k}_{4}, 0\right)\right\} \\
& \text { if fs }{ }_{\mathrm{a}}{ }_{\mathrm{a}}\left(\mathrm{o}_{\mathrm{z}}\right)=\left\{\left(\mathrm{k}_{1}, 0\right),\left(\mathrm{k}_{2}, 0\right),\left(\mathrm{k}_{3}, 1\right),\left(\mathrm{k}_{4}, 0\right)\right\}^{\gamma} \text { then fs }{ }_{\mathrm{a}}{ }_{\mathrm{a}}\left(\mathrm{o}_{\mathrm{z}}\right)=\left\{\left(\mathrm{k}_{1}, 0\right),\left(\mathrm{k}_{2}, 0\right),\left(\mathrm{k}_{3}, \mathrm{f}_{3}(1, \gamma)\right),\left(\mathrm{k}_{1}, 0\right)\right\} \\
& \text { if fs }{ }_{\mathrm{a}}{ }_{\mathrm{a}}\left(\mathrm{o}_{\mathrm{z}}\right)=\left\{\left(\mathrm{k}_{1}, 0\right),\left(\mathrm{k}_{2}, 0\right),\left(\mathrm{k}_{3}, 0\right),\left(\mathrm{k}_{4}, 1\right)\right\}^{\gamma} \text { then fs }{ }_{\mathrm{a}}{ }_{\mathrm{a}}\left(\mathrm{o}_{\mathrm{z}}\right)=\left\{\left(\mathrm{k}_{1}, 0\right),\left(\mathrm{k}_{2}, 0\right),\left(\mathrm{k}_{3}, 0\right),\left(\mathrm{k}_{4}, \mathrm{f}_{4}(1, \gamma)\right)\right\} \\
& \text { if fs }{ }_{\mathrm{a}}{ }_{\mathrm{a}}\left(\mathrm{o}_{\mathrm{z}}\right)=\left\{\left(\mathrm{k}_{1}, 0\right),\left(\mathrm{k}_{2}, 0.5\right),\left(\mathrm{k}_{3}, 0.5\right),\left(\mathrm{k}_{4}, 0\right)\right\}^{\gamma} \text { then } \\
& \text { fs }^{2}{ }_{\mathrm{a}}=\left\{\left(\mathrm{k}_{1}, 0\right),\left(\mathrm{k}_{2}, \mathrm{f}_{5}(0.5, \gamma)\right),\left(\mathrm{k}_{3}, \mathrm{f}_{5}(0.5, \gamma)\right),\left(\mathrm{k}_{4}, 0\right)\right\}
\end{aligned}
$$


if fs ${ }_{\mathrm{a}}{ }_{\mathrm{a}}\left(\mathrm{o}_{\mathrm{z}}\right)=\left\{\left(\mathrm{k}_{1}, 0.3\right),\left(\mathrm{k}_{2}, 0.3\right),\left(\mathrm{k}_{3}, 0.3\right),\left(\mathrm{k}_{4}, 0\right)\right\}^{\gamma}$ then $\mathrm{fs}^{2}{ }_{\mathrm{a}}\left(\mathrm{o}_{\mathrm{z}}\right)=\left\{\left(\mathrm{k}_{1}, \mathrm{f}_{6}(0.3, \gamma)\right)\right.$, $\left.\left(\mathrm{k}_{2}, \mathrm{f}_{6}(0.3, \gamma)\right),\left(\mathrm{k}_{3}, \mathrm{f}_{6}(0.3, \gamma)\right),\left(\mathrm{k}_{4}, 0\right)\right\}$, where $\mathrm{f}_{\mathrm{p}}$ is the membership function of the object $\mathrm{o}_{\mathrm{z}} \in \mathrm{O}$ to the class of objects $\mathrm{O}_{\mathrm{p}}\left(\mathrm{t}_{\mathrm{k}}\right), \quad \mathrm{p} \in\{1,2, \ldots, 6\}$ and is defined as: $\mathrm{f}_{\mathrm{p}}:\{1,0.5,0.3\} \times\{1,0.7,0.4\} \rightarrow(0,1]$

Remark: For each $\mathrm{fs}^{1}{ }_{\mathrm{a}}\left(\mathrm{o}_{\mathrm{z}}\right)$ only one value $\delta_{\mathrm{p}}$ of the membership function $\mathrm{f}_{\mathrm{p}}$ $\mathrm{p} \in\{1,2, \ldots, 6\}$ is computed; $\mathrm{f}_{\mathrm{p}}\left(\alpha_{\mathrm{p}}, \gamma\right)=\alpha_{\mathrm{p}} \cdot \gamma$

Step 3. Compute fuzzy set representative $\operatorname{fsr}^{2}\left(\mathrm{o}_{z}\right)$ of all second-level fuzzy set representations $\mathrm{fs}^{2}{ }_{\mathrm{a}}\left(\mathrm{o}_{\mathrm{z}}\right), \mathrm{a}=1,2, \ldots, \operatorname{card}\left(\mathrm{A}^{\prime}\right): \mathrm{fsr}^{2}\left(\mathrm{o}_{\mathrm{z}}\right)=\left\{\left(\mathrm{k}_{1}, \Theta_{1}\right),\left(\mathrm{k}_{2}, \Theta_{2}\right),\left(\mathrm{k}_{3}, \Theta_{3}\right),\left(\mathrm{k}_{4}, \Theta_{4}\right)\right\}$,

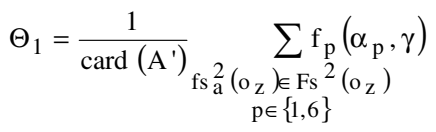

$$
\begin{aligned}
& \Theta_{2}=\frac{1}{\operatorname{card}\left(\mathrm{A}^{\prime}\right)} \sum_{\substack{\mathrm{fs}_{\mathrm{a}}^{2}\left(\mathrm{o}_{\mathrm{z}}\right) \in \mathrm{Fs}^{2}\left(\mathrm{o}_{\mathrm{z}}\right) \\
\mathrm{p} \in\{2,5,6\}}} \mathrm{f}_{\mathrm{p}}\left(\alpha_{\mathrm{p}}, \gamma\right)
\end{aligned}
$$

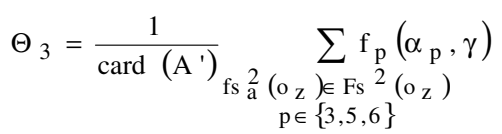

$$
\begin{aligned}
& \Theta_{4}=\frac{1}{\operatorname{card}\left(\mathrm{A}^{\prime}\right)} \underset{\mathrm{fs}_{\mathrm{a}}^{2}\left(\mathrm{o}_{\mathrm{z}}\right) \in \mathrm{Fs}^{2}\left(\mathrm{o}_{\mathrm{z}}\right)}{\mathrm{f}_{4}\left(\alpha_{\mathrm{p}}, \gamma\right)}
\end{aligned}
$$

$\mathrm{Fs}^{2}\left(\mathrm{O}_{\mathrm{z}}\right)$ is the set of all second-level fuzzy set representations.

Step 4. Apply the procedure of the choice of consensus description of the state of object $\mathrm{o}_{\mathrm{z}}$ [see 5].

Stop.

\section{Final Remarks}

In this paper a strategy of integration of agents' prepositional attitudes was proposed in order to solve the semantic inconsistency between agents' opinions. The receiver of the messages applies the algorithm for the prepositional attitudes integration. In this algorithm all the agents' answers are transformed into fuzzy set equivalents and then the formula representing the agreement of all opinions is obtained.

\section{References}

1. Coradeschi S., Saffiotti A., An Introduction to the Anchoring Problem, Robotics and Autonomous Systems 43, (2003), 85-96

2. Harnad, S.:The Symbol Grounding Problem. Physica, 42, 335-236

3. Katarzyniak, R., Pieczynska-Kuchtiak, A.: A Consensus Based Algorithm for Grounding Belief formulas in Internally Stored Perceptions. Neural Network World, 5, (2002) 671-682

4. Katarzyniak, R., Pieczynska-Kuchtiak, A.: Grounding and extracting modal responses in cognitive agents: AND query and states of incomplete knowledge. International Journal of Applied Mathematics and Computer Science, 14(2), (2004), 249-263.

5. Katarzyniak, R., Pieczynska-Kuchtiak, A.: An Approach to resolving semantic inconsistency of multiple prepositional attitudes. Journal of Intelligent \& Fuzzy Systems 17(3), (2006), (to appear).

6. Pieczynska-Kuchtiak, A., Towards measure of semantic correlation between messages in multiagent system, ICCS 2005, Lecture Notes on Computer Science, Kraków, (2004) pp. 567-574.

7. Vogt P., Anchoring of semiotics symbols, Robotics and Autonomous Systems, 43, (2003) 109-120. 